\title{
Intraoperative assessment of reduction and implant placement in acetabular fractures-limitations of 3D-imaging compared to computed tomography
}

Holger Keil ${ }^{\dagger}$, Nils Beisemann ${ }^{\dagger}$, Marc Schnetzke, Sven Yves Vetter, Benedict Swartman, Paul Alfred Grützner and Jochen Franke* (1)

\begin{abstract}
Background: In acetabular fractures, the assessment of reduction and implant placement has limitations in conventional 2D intraoperative imaging. 3D imaging offers the opportunity to acquire CT-like images and thus to improve the results. However, clinical experience shows that even 3D imaging has limitations, especially regarding artifacts when implants are placed. The purpose of this study was to assess the difference between intraoperative 3D imaging and postoperative $\mathrm{CT}$ regarding reduction and implant placement.

Methods: Twenty consecutive cases of acetabular fractures were selected with a complete set of intraoperative 3D imaging and postoperative CT data. The largest detectable step and the largest detectable gap were measured in all three standard planes. These values were compared between the 3D data sets and CT data sets. Additionally, possible correlations between the possible confounders age and BMl and the difference between $3 \mathrm{D}$ and $\subset T$ values were tested.

Results: The mean difference of largest visible step between the 3D imaging and CT scan was $2.0 \pm 1.8 \mathrm{~mm}(0.0-5.8$, $p=0.02)$ in the axial, $1.3 \pm 1.4 \mathrm{~mm}(0.0-3.7, p=0.15)$ in the sagittal and $1.9 \pm 2.4 \mathrm{~mm}(0.0-7.4, p=0.22)$ in the coronal views. The mean difference of largest visible gap between the $3 D$ imaging and $C T$ scan was $3.1 \pm 3.6 \mathrm{~mm}(0.0-14.1$, $p=0.03)$ in the axial, $4.6 \pm 2.7 \mathrm{~mm}(1.2-8.7, p=0.001)$ in the sagittal and $3.5 \pm 4.0 \mathrm{~mm}(0.0-15.4, p=0.06)$ in the coronal views. A positive correlation between the age and the difference in gap measurements in the sagittal view was shown (rho $=0.556, p=0.011$ ).
\end{abstract}

Conclusions: Intraoperative 3D imaging is a valuable adjunct in assessing reduction and implant placement in acetabular fractures but has limitations due to artifacts caused by implant material. This can lead to missed malreduction and impairment of clinical outcome, so postoperative CT should be considered in these cases.

Keywords: Intraoperative 3D imaging, Acetabular fracture, Computed tomography, Trauma

\section{Background}

The acetabulum is the pelvic part of the hip joint, being formed by the ischium, ilium, and the pubis. It is a central part of the musculoskeletal system and needs to bear heavy forces due to the large range of motion of the hip joint and weight supply during walking and running.

\footnotetext{
* Correspondence: jochen.franke@bgu-ludwigshafen.de

${ }^{\dagger}$ Equal contributors

Clinic for Trauma and Orthopaedic Surgery, BG Trauma Center Ludwigshafen at the University of Heidelberg, MINTOS - Medical Imaging and Navigation in Trauma and Orthopaedic Surgery, Ludwig-Guttmann-Str. 13, 67071 Ludwigshafen, Germany
}

Thus, the microstructure of the acetabulum provides a very stable counterpart to the femoral head. Biomechanically, there are two bony regions that transfer the load towards the pelvic ring and the spine, referred to as anterior and posterior column.

Fractures of the acetabulum are rather rare fractures with an incidence of about 5 per 100,000 people per year, especially when compared to the incidence of proximal femur fractures that show an up to hundred-fold higher incidence, depending on the geographical region [1]. Like other fractures, acetabular fractures show a 
bimodal distribution. There is a peak in young, rather male patients due to high-energy traumata, for example, due to vehicle collisions or fall from height and a second peak in elder, rather female patients due to low-energy traumata combined with decreased bone density.

Due to the complex anatomy with soft tissue coverage, strong muscle tear on the inner and outer surface of the acetabulum and a concave joint surface, the assessment of the articular joint surface with intraoperative 2D imaging is limited. The crucial aspect is the weight-bearing zone of the acetabular roof where steps and gaps need to be reduced as far as possible.

Depending on the fracture type, typical surgical approaches include the Kocher-Langenbeck approach to the posterior column, and the Stoppa- as well as the ilio-inguinal approach to the anterior column. Usually, the osteosynthesis is done with $3.5 \mathrm{~mm}$ plates combined with single lag screws, if necessary. To increase mechanical stability of the fitting, it may be helpful to position screws close to the acetabular surface. Due to the abovementioned aspects of the anatomical situation, assessing these screws in 2D imaging is extremely challenging and it is not always possible to precisely exclude extraarticular positioning [2].

As in acetabular fractures, there are several other anatomical regions that can only be assessed very limited in 2D imaging due to concave joint surfaces and anatomical configuration. This includes fractures of the tibial head as well as the calcaneus, ankle injuries involving the syndesmosis, and spinal injuries [3-6]. To improve the surgeon's possibilities to assess the result of the reduction and osteosynthesis intraoperatively, intraoperative 3D imaging with a mobile $\mathrm{C}$-arm has been available since 2001. These devices create computed tomography (CT-) like datasets by motorized movement of the Carm around the patient and automatized acquisition of images. These images are converted to 3D volumes by methods comparable to CT-reconstruction and can be assessed directly by the surgeon. With the help of this technique, it is possible to intraoperatively exclude malreduction of the fracture and misplacement of implants. Usually, the 3D scan is performed when reduction and implant placement are considered correct in fluoroscopy. Several studies show intraoperative revision rates depending on the anatomical region of up to $40 \%$ as a consequence of the 3D imaging [7-10]. Due to these results, 3D imaging has become very common in the operative treatment of complex articular fractures.

In our institution, a 3D scan is performed in every acetabular fixation when reduction and implant placement is considered to be correct. Usually, a postoperative CT scan is not necessary as reduction and implant placement are evaluated intraoperatively. There are special circumstances, however, when a postoperative CT scan is performed. This includes two-column fractures with a two-stage approach. In these cases, usually a CT scan is performed for evaluating the whole pelvic anatomy after the first stage to be able to anticipate the second stage. Other indications include control scans of retroperitoneal hematomas or diagnostic scans for abdominal complains. In these scans, sometimes discrepancies to the intraoperative 3D scans were noticed regarding remaining steps and gaps that were not visible in the $3 \mathrm{D}$ scans, especially due to artifacts resulting from the implants.

The aim of this retrospective study was to evaluate the image quality and assessability of intraoperative 3D scans compared to postoperative $\mathrm{CT}$ scans regarding visible steps and gaps in the articular surface of the acetabulum.

\section{Methods}

Anonymized image sets from patients that were operated on the acetabulum and received an intraoperative $3 \mathrm{D}$ as well as a postoperative CT scan before ambulation was included in this study.

The intraoperative scans were performed using the 3D $\mathrm{C}$-arm Arcadis Orbic (Siemens, Erlangen, Germany). The postoperative CT scans were performed by the radiological department with a clinical 32-slice CT scanner (Aquilion 32, Toshiba, Japan).

Multiplanar reconstructions of the 3D data were performed to match the standard reconstruction views of the $\mathrm{CT}$ scans done by the radiological department (orthogonal views in standard axial, coronal, and sagittal orientation). To achieve comparable conditions for assessing the 3D data as well as the CT data, slice reconstruction thickness was set to $2 \mathrm{~mm}$ in all MPRs of as well 3D as CT data.

All images were assessed regarding the largest visible step and largest visible gap in each plane. "Largest" was defined as the measurement in the slice where the distinct distance between the two ends of the step, respectively gap, as described below was clearly identifiable. This was done with the use of high-contrast displays with free arrangement of contrast, brightness, and zoom by the examiner using the standard clinical PACS viewer (Impax, Agfa, Belgium). All images were assessed by two members of the research group (MS, who is an experienced consultant and NB, who is a resident), and the average values of the measurements were used for further analysis.

Steps were measured in relation to the remaining articular surface. A line through the center of the femoral head was used to measure the exact distance (see Fig. 1). This was done for the largest step that was clearly identifiable in the current slice. The procedure was repeated for all three planes. 


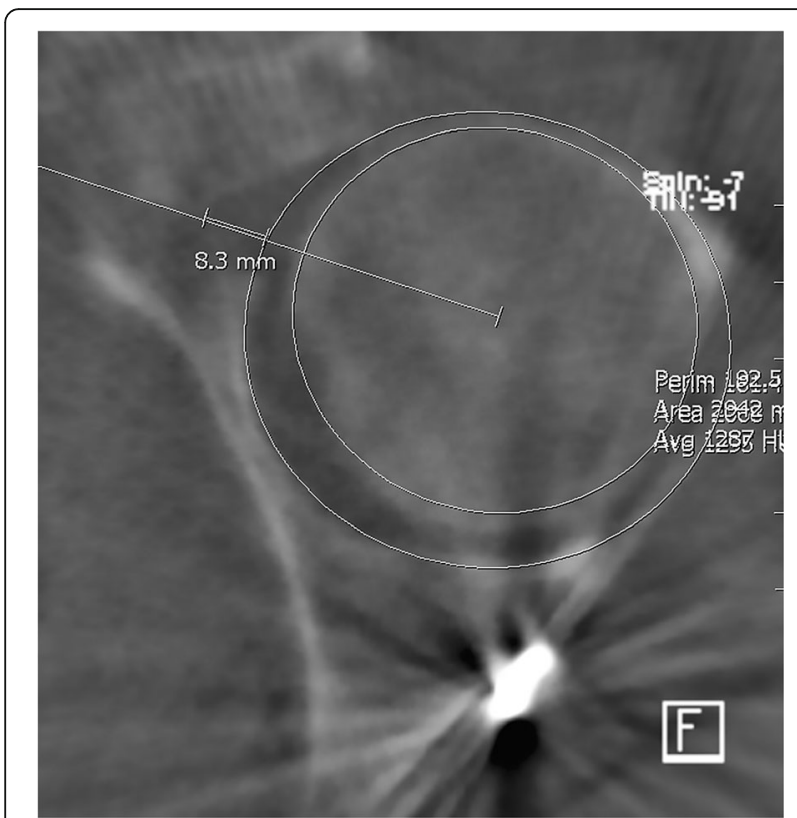

Fig. 1 Example of intraoperative 3D scan (axial plane) with measurement lines for steps

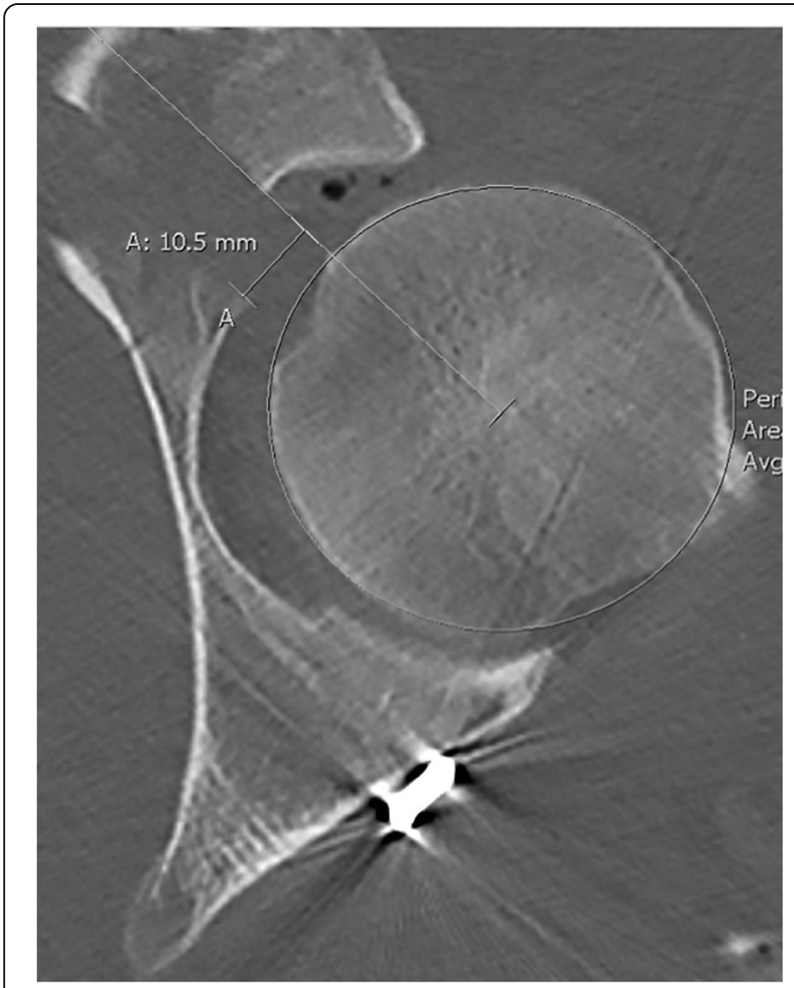

Fig. 2 Example of postoperative CT scan (axial plane) with measurement lines for gaps
Table 1 Assessability score for the 3D scan data

\begin{tabular}{ll}
\hline $\begin{array}{l}\text { Cortical bone of the femoral head } \\
\text { is visible in all slices }\end{array}$ & Yes \\
$\begin{array}{l}\text { Subchondral bone of the acetabulum } \\
\text { is visible in more than } 2 / 3 \text { of all slices }\end{array}$ & 1 \\
Points & Result \\
0 & Major limitations \\
1 & Minor limitations \\
2 & No limitations \\
\hline
\end{tabular}

Gaps were measured relating to the virtual continuation of the articular surface. A line through the center of the femoral head was used as a reference for the distance of the distal fragment to the remaining articular surface. The least distance was used as the value for the gap (see Fig. 2).

In cases with minor or major limitations of the assessability, meaning relevant parts of the acetabular surface were overlapped by artifacts, only distinct steps and gaps were measured. Following this, if relevant steps or gaps were overlapped, they were not covered by the measurement and thus leading to underestimation of the values.

To illustrate the impact of underestimation, relative differences were calculated. For statistical analysis, the absolute value of the difference between the values measured in the 3D scans and those measured in the CT scans was used to avoid value balancing by relative differences.

The image data of the 3D scans were assessed regarding the visibility of the articular surface of the acetabulum and the femoral head according to the score shown in Table 1:

All radiological data were assessed in randomized order independently by two physicians.

Additionally, the following demographic data was collected from the patient records:

- Age

- Mechanism of accident

- Body mass index (BMI)

- Days to surgery

- Injury type (AO classification)

The following perioperative data was also analyzed:

- Duration of surgery

Table 2 Distribution of the fracture types according to the AO classification

\begin{tabular}{llllllllll}
\hline Fracture type & A1 & A2 & A3 & B1 & B2 & B3 & C1 & C2 & C3 \\
Frequency & 1 & 1 & 2 & 1 & 0 & 3 & 1 & 9 & 2 \\
\hline
\end{tabular}


Table 3 Mean values of the largest visible step in the 3D and CT scans

\begin{tabular}{|c|c|c|c|c|c|c|}
\hline Steps $[\mathrm{mm}]$ & Axial & $p$ value & Sagittal & $p$ value & Coronal & $p$ value \\
\hline 3D scan & $1.14 \pm 1.81$ & & $1.06 \pm 1.49$ & & $1.68 \pm 1.46$ & \\
\hline CT scan & $2.87 \pm 2.69$ & & $1.95 \pm 2.18$ & & $3.14 \pm 3.14$ & \\
\hline Relative difference (3D-CT) & $-1.74 \pm 2.00$ & & $-0.89 \pm 1.71$ & & $-1.46 \pm 2.71$ & \\
\hline Absolute difference & $1.96 \pm 1.78$ & $0.024^{*}$ & $1.32 \pm 1.38$ & 0.149 & $1.88 \pm 2.42$ & 0.221 \\
\hline
\end{tabular}

Values marked with an asterisk $\left(^{*}\right)$ show statistical significance

- Applied blood products (packed red blood cells, RBC and fresh frozen plasma, FFP)

- Number of intraoperative 3D scans (in case of multiple scans, only the last one was used for this study)

- Intraoperative revision due to findings in the 3D scan

Age was considered as a potential parameter for decreased bone density (and thus decreased contrast in Xray examinations) and was tested for correlation to the mean difference values using Spearman's rho.

The BMI was considered as a parameter for the amount of soft tissue surrounding the acetabulum and thus confine image quality in both $2 \mathrm{D}$ and $3 \mathrm{D}$ images and tested for correlation to the mean difference values using Spearman's rho.

Statistical analysis was done with SPSS Version 23 (IBM, USA). Comparison of mean values was performed with Student's $t$ test. Correlation was tested with Spearman's rho. Statistical significance was assumed when $p<0.05$.

\section{Results}

Twenty consecutive image sets of patients ( 9 males and 11 females) that were operated between August 2012 and May 2016 were included in this study. The mean age was $44.0 \pm 18.6[15.4-82.1]$ years. In 11 cases, the mechanism of the accident was a high-energy vehicle crash, in 3 cases a bicycle crash and in 6 cases a fall from height.

The mean BMI was $24.5 \pm 4.3[19.2-36.7] \mathrm{kg} / \mathrm{m}^{2}$, the average time between the accident and surgery was 7.9 $\pm 4.5[0-19]$ days.

The distribution of fracture types according to the AO classification is shown in Table 2.

Six patients $(30 \%)$ were operated with a two-step approach, and 14 patients $(70 \%)$ were operated with a one- step approach. In 13 cases (65\%), additional cannulated screws were placed in the acetabular dome. The mean duration of surgery was $250.0 \pm 103.7$ [71-411] min. A mean of $1.7 \pm 1.7$ [0-5] units of packed red blood cells and $0.4 \pm$ $0.9[0-3]$ units of fresh frozen plasma were dispensed.

There were no serious peri- or postoperative complications like major bleeding, circulatory depression, neurological, or urological deficits.

In four cases (20\%), an intraoperative correction of the reduction or implant placement was done as a result of the 3D imaging. In all cases, an additional 3D scan was performed after the correction to ensure the resulting reduction and implant position.

The assessability score (see Table 1) was 0 (major limitations) in 2 cases (10\%), 1 (minor limitations) in 9 cases (45\%) and 2 (no limitations) in 9 cases (45\%).

The mean absolute values for the differences between the measurements in the $3 \mathrm{D}$ scan and the $\mathrm{CT}$ scans are shown in Tables 3 and 4. As shown, there was statistical significance regarding the values of visible steps in the axial views $(p=0.024)$ as well as the values of visible gaps in the axial $(p=0.030)$ and sagittal $(p=0.001)$ views. As the absolute values of the difference in the measurements were used, the absolute difference is not the difference between the displayed mean values for the modalities.

The results of correlation analysis of the BMI and age with the absolute difference values of the measurements are shown in Table 5 . The only significant correlation with a coefficient of 0.556 was between age and the mean difference in the measurement of the sagittal gap $(p=0.011)$.

\section{Discussion}

As acetabular fractures are articular fractures, even minor impairments of the articular surface due to

Table 4 Mean values of the largest visible gap in the 3D and CT scans

\begin{tabular}{|c|c|c|c|c|c|c|}
\hline Gaps [mm] & Axial & $p$ value & Sagittal & $p$ value & Coronal & $p$ value \\
\hline 3D scan & $3.42 \pm 3.32$ & & $2.02 \pm 3.89$ & & $2.45 \pm 1.81$ & \\
\hline CT scan & $6.41 \pm 4.71$ & & $5.87 \pm 3.61$ & & $4.91 \pm 4.67$ & \\
\hline Relative difference (3D-CT) & $-2.99 \pm 3.75$ & & $-3.85 \pm 3.73$ & & $-2.46 \pm 4.71$ & \\
\hline Absolute difference & $3.14 \pm 3.61$ & $0.030^{*}$ & $4.57 \pm 2.74$ & $0.001^{*}$ & $3.50 \pm 3.96$ & 0.060 \\
\hline
\end{tabular}

Values marked with an asterisk (*) show statistical significance 
Table $5 p$ values of the correlation analysis of age and BMI with the differences in the measurements

\begin{tabular}{lllllll}
\hline & Step axial & Step sagittal & Step coronal & Gap axial & Gap sagittal & Gap coronal \\
\hline BMl & 0.110 & 0.310 & 0.235 & 0.915 & 0.409 & 0.158 \\
Age & 0.492 & 0.848 & 0.942 & 0.433 & $0.011^{*}$ & 0.955 \\
\hline
\end{tabular}

Values marked with an asterisk $\left(^{*}\right)$ show statistical significance

displaced fracture parts can induce rapid progress of osteoarthritis and thus cause a severe disability. Following this, the scope for conservative treatments of these fractures is shallow and usually only displacements of less than $2 \mathrm{~mm}$ in the main weight bearing zone can be tolerated to achieve an acceptable clinical outcome [11]. So, open reduction and internal fixation is the method of choice in many cases. In open reduction, anatomical reduction is crucial for the outcome of these fractures to avoid early need for total hip arthroplasty what is associated with higher mortality and impairment $[12,13]$.

The possibility to intraoperatively acquire 3D data of a surgical field to evaluate reduction and implant placement is a valuable adjunct to $2 \mathrm{D}$ fluoroscopy as shown in several studies $[5,14,15]$. Often, these 3D scans are considered equal to CT scans regarding the parameters reduction and implant placement. Standardized technical evaluation of possible image quality of intraoperative and image quality in anatomical regions without implants has been described in several publications $[16,17]$.

However, the technical means of image acquisition differ between the two methods. In 3D C-arms, a set of 2D images (typically 50 to 100) is acquired during an automatized rotation around the region of interest. The 3D data is computed from these images. This limits the size of the 3D volume to a cube with an edge length of typically $12-14 \mathrm{~cm}$. Additionally, due to the non-continuous data, the contrast discrimination is lower than in CT data and the data is more prone to implant artifact disturbances. CT data on the other hand is usually acquired during a continuous emittance of radiation which increases the amount of data available for image reconstruction. Thus, CT data usually has a higher contrast discrimination and is less disturbed by metal implants as there are more data available for metal artifact reduction algorithms [18, 19].

In most cases, though, the quality of $3 \mathrm{D}$ data acquired by $3 \mathrm{D} \mathrm{C}$-arms is sufficient to assess reduction and implant placement as demonstrated by many groups in literature that show a good assessability of the $3 \mathrm{D}$ data $[7$, $9,10,20-22]$. However, in the special circumstance of displaced acetabular fractures with many metal implants close to the articular surface, relevant remaining steps and gaps can be missed in the intraoperative 3D imaging (see Fig. 3) what was shown in this study. This implies that the surgeon, who evaluates the imaging does not only have to assess the detectable joint line regarding reduction and the implant placement but also to judge if the $3 \mathrm{D}$ imaging itself is sufficient regarding the visible joint line and areas blurred by artifacts.

As shown in the evaluation of the 3D and CT data, the values for steps and gaps are rather underestimated in intraoperative 3D data. This might arise from the fact that, if large parts of the acetabular surface are not visible due to metal artifacts, possible steps and gaps are overlapped by these and thus not measured. This point emphasizes the need for proper assessment of the overall appropriateness of the intraoperative imaging as remaining relevant steps or gaps can be worse regarding the outcome than a separate revision surgery.

There are few papers that deal with the impact of the BMI on image quality. Usually, it is described that in stationary CT scanners, the patient dose is increased in obese patients $[23,24]$. In intraoperative settings, the

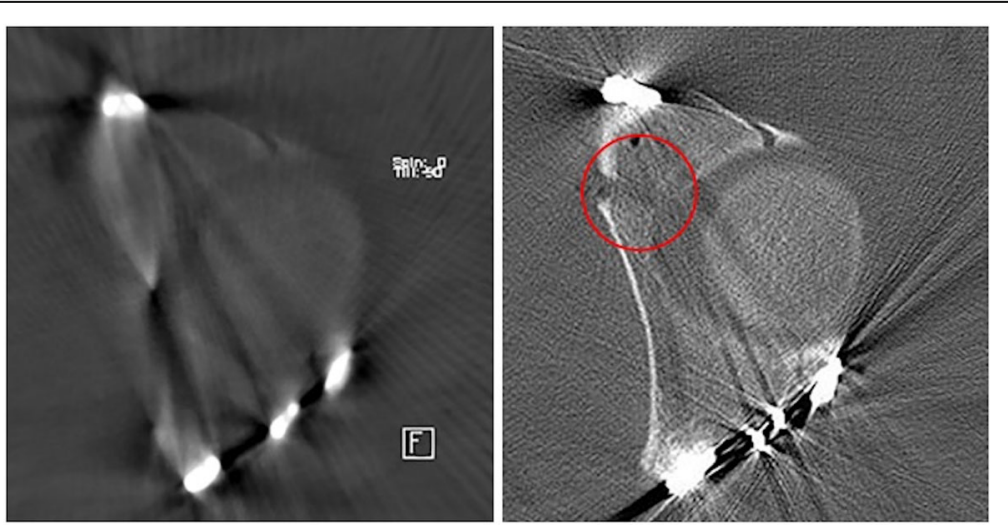

Fig. 3 Illustration of blurring of a gap in the articular surface due to metal artifacts in the 3D scan. In the CT scan, the gap is clearly visible (red circle) 
dose often cannot be increased due to power limitations. Thus, it was expected, that the BMI would have a significant impact on the assessability of the imaging. In this study, this could not be evidenced, what might be due to the rather low BMI values in our rather young collective.

Also, the correlation between the age of the patient and the assessability was only significant in the measurement values for the largest visible gap in the sagittal plane, thus not showing a strong correlation. It was assumed that age would accompany with decreased bone mineralization and thus hindered assessability in the 3D scans. There is some literature regarding the experiences in the cone beam computed tomography of the head that could show a negative correlation between age and image quality [25]. Probably, due to the small group size and rather young patients, this could not be shown.

The 3D C-arm that was used in this study represents the current clinical standard-an image intensifier based mobile $\mathrm{C}$-arm. Recently, new types of 3D C-arms with flat panel detectors as well as intraoperative CTsolutions have been announced or released. These novel devices promise a significant improvement of artifact reduction and contrast resolution and have to be reevaluated as soon as they become clinically available.

\section{Conclusions}

In this study it was demonstrated that there are situations when steps and gaps can be missed in the intraoperative 3D imaging, especially in complex fracture situations with a high implant load close to the joint surface. In these cases, one should be aware of the potential diagnostic gap and perform a postoperative CT to ensure reduction quality and implant placement.

\section{Abbreviations}

BMI: Body mass index; CT: Computed tomography; FFP: Fresh frozen plasma; PACS: Picture Archiving and Communication System; RBC: Red blood cells

\section{Acknowledgements}

We acknowledge financial support by Deutsche Forschungsgemeinschaft within the funding programme Open Access Publishing, by the Baden-Württemberg Ministry of Science, Research and the Arts and by Ruprecht-Karls-Universität Heidelberg.

\section{Funding}

The MINTOS research group receives funding by Siemens Healthcare, Forchheim, Germany.

Non-financial competing interests: no non-financial competing interests exist for any of the authors.

\section{Availability of data and materials}

The datasets generated and analyzed during the current study are available from the corresponding author on reasonable request.

\section{Authors' contributions}

HK wrote the manuscript. MS and NB did the measurements. BS and SY developed the concept and the modalities. PG and JF supervised the study and assisted with the concept. All authors read and approved the final manuscript.
Ethics approval and consent to participate

This article does only contain studies with anonymized data; therefore, after inquiry with the ethics commission of the medical association of RhinelandPalatinate, no ethical approval was needed.

\section{Consent for publication}

Not applicable.

\section{Competing interests}

Paul Grützner and Jochen Franke are paid lecturers for Siemens Healthcare, Forchheim, Germany.

\section{Publisher's Note}

Springer Nature remains neutral with regard to jurisdictional claims in published maps and institutional affiliations.

Received: 14 February 2018 Accepted: 23 March 2018

Published online: 10 April 2018

References

1. Johnel O, Gullberg B, Allander E, Kanis JA. The apparent incidence of hip fracture in Europe: a study of national register sources. Osteoporos Int. 1992;2:298-302.

2. Kendoff D, Gardner MJ, Citak M, Kfuri M, Thumes B, Krettek C, et al. Value of 3D fluoroscopic imaging of acetabular fractures comparison to 2D fluoroscopy and CT imaging. Arch Orthop Trauma Surg. 2008;128:599-605.

3. Oberst M, Hauschild O, Konstantinidis L, Suedkamp NP, Schmal H. Effects of three-dimensional navigation on intraoperative management and early postoperative outcome after open reduction and internal fixation of displaced acetabular fractures. J Trauma Acute Care Surg. 2012;73:950-6. Available from: http://www.ncbi.nlm.nih.gov/pubmed/22710769. [cited 7 Apr 2017]

4. Khoury A, Siewerdsen JH, Whyne CM, Daly MJ, Kreder HJ, Moseley DJ, et al. Intraoperative cone-beam CT for image-guided tibial plateau fracture reduction. Comput Aided Surg. 2007;12:195-207.

5. von Recum J, Wendl K, Vock B, Grützner PA, Franke J. [Intraoperative 3D Carm imaging. State of the art]. Unfallchirurg. 2012;115(3):196-201. Available from: http://www.ncbi.nlm.nih.gov/pubmed/22367513.

6. Franke J, von Recum J, Suda AJ, Grützner PA, Wendl K. Intraoperative threedimensional imaging in the treatment of acute unstable syndesmotic injuries. J Bone Jt Surgery-American Vol. 2012;94:1386-90. Available from: http://www.ncbi.nlm.nih.gov/pubmed/22854991. [cited 7 Apr 2017]

7. Beerekamp MSH (Suzan), GSI S, Ubbink DT, Maas M, NWL S, Goslings JC. Accuracy and consequences of 3D-fluoroscopy in upper and lower extremity fracture treatment: a systematic review. Eur J Radiol. 2012;81:4019-28. Available from: http://www.ncbi.nlm.nih.gov/pubmed/22975150. [cited 7 Apr 2017]

8. Beck M, Rotter R, Gradl G, Herlyn P, Kröber M, Mittlmeier T, et al. Reliability and consequences of intraoperative 3D imaging to control positions of thoracic pedicle screws. Arch Orthop Trauma Surg. 2012;132:1371-7. Available from: http://www.ncbi.nlm.nih.gov/pubmed/22699397. [cited 7 Apr 2017]

9. Eckardt $\mathrm{H}$, Lind $\mathrm{D}$, Toendevold $\mathrm{E}$. Open reduction and internal fixation aided by intraoperative 3-dimensional imaging improved the articular reduction in 72 displaced acetabular fractures. Acta Orthop. 2015;86:684-9. Available from: http://www.ncbi.nlm.nih.gov/pubmed/26012545. [cited 7 Apr 2017]

10. Vetter SY, Euler F, von Recum J, Wendl K, Gru tzner PA, Franke J. Impact of intraoperative cone beam computed tomography on reduction quality and implant position in treatment of Tibial plafond fractures. Foot Ankle Int. 2016;37:977-82. Available from: http://www.ncbi.nlm.nih.gov/pubmed/ 27188693. [cited 2 Mar 2017]

11. Matta JM, Anderson LM, Epstein HC, Hendricks P. Fractures of the acetabulum. A retrospective analysis. Clin Orthop Relat Res. 1986:230-40. Available from: http://www.ncbi.nlm.nih.gov/pubmed/3698382

12. Dunet B, Tournier C, Billaud A, Lavoinne N, Fabre T, Durandeau A. Acetabular fracture: long-term follow-up and factors associated with secondary implantation of total hip arthroplasty. Orthop Traumatol Surg Res. 2013;99:281-90. Available from: http://www.ncbi.nlm.nih.gov/pubmed/ 23562708. [cited 24 Aug 2017]

13. Morison Z, Moojen DJF, Nauth A, Hall J, McKee MD, Waddell JP, et al. Total hip arthroplasty after acetabular fracture is associated with lower survivorship and more complications. Clin Orthop Relat Res. 2016;474: 392-8. Available from: http://www.ncbi.nlm.nih.gov/pubmed/26335343. [cited 24 Aug 2017] 
14. Schwabe P, Altintas B, Schaser K-D, Druschel C, Kleber C, Haas NP, et al. Three-dimensional fluoroscopy-navigated percutaneous screw fixation of acetabular fractures. J Orthop Trauma. 2014;28:700-6. Available from: http://www.ncbi.nlm.nih.gov/pubmed/24662989. [cited 7 Apr 2017]

15. Sebaaly A, Riouallon G, Zaraa M, Jouffroy P. The added value of intraoperative $C T$ scanner and screw navigation in displaced posterior wall acetabular fracture with articular impaction. Orthop Traumatol Surg Res. 2016;102:947-50. Available from: http://www.ncbi.nlm.nih.gov/pubmed/ 27527248. [cited 7 Apr 2017]

16. Stuby F, Seethaler AC, Shiozawa T, Weise K, Mroue A, Badke A, et al. Evaluation of image quality of two different three-dimensional cone-beamscanners used for orthopedic surgery in the bony structures of the pelvis in comparison with standard CT scans. Z Orthop Unfall. 2011;149:659-67. Available from: http://www.ncbi.nlm.nih.gov/pubmed/21590660

17. Seeberger R, Buchgeister M, Seethaler AC, Shiozawa T, Hoffmann J. Image quality of two different mobile cone beam computed tomographs for maxillofacial surgery. J Cranio-Maxillofacial Surg. 2012;40:731-4. Available from: http://www.ncbinlm.nih.gov/pubmed/22361302. [cited 22 Aug 2017]

18. Pessis E, Sverzut J-M, Campagna R, Guerini H, Feydy A, Drapé J-L. Reduction of metal artifact with dual-energy $C T$ : virtual monospectral imaging with fast kilovoltage switching and metal artifact reduction software. Semin Musculoskelet Radiol. 2015;19:446-55. Available from: http://www.ncbi.nlm. nih.gov/pubmed/26696083. [cited 24 Aug 2017]

19. Huang JY, Kerns JR, Nute JL, Liu X, Balter PA, Stingo FC, et al. An evaluation of three commercially available metal artifact reduction methods for CT imaging. Phys Med Biol. 2015;60:1047-67. Available from: http://www.ncbi. nlm.nih.gov/pubmed/25585685. [cited 24 Aug 2017]

20. Schnetzke M, Fuchs J, Vetter SY, Beisemann N, Keil H, Grützner P-A, et al. Intraoperative 3D imaging in the treatment of elbow fractures-a retrospective analysis of indications, intraoperative revision rates, and implications in 36 cases. BMC Med Imaging. 2016;16:24. Available from: http://www.ncbi.nlm.nih.gov/pubmed/26987661. [cited 7 Apr 2017]

21. Carelsen B, Haverlag R, Ubbink DT, Luitse JSK, Goslings JC. Does intraoperative fluoroscopic 3D imaging provide extra information for fracture surgery? Arch Orthop Trauma Surg. 2008:128:1419-24. Available from: http://www.ncbi.nlm. nih.gov/pubmed/18791727. [cited 2017 Apr 2017]

22. Kraus $\mathrm{M}$, Fischer $\mathrm{E}$, Gebhard F, Richter PH. Image quality and effective dose of a robotic flat panel 3D C-arm vs computed tomography. Int J Med Robot Comput Assist Surg. 2016;12:743-50. Available from: http://www.ncbi.nlm. nih.gov/pubmed/26678361. [cited 24 Aug 2017]

23. You J, Dai Y, Huang N, Li J-J, Cheng L, Zhang X-L, et al. Low-dose computed tomography with adaptive statistical iterative reconstruction and low tube voltage in craniocervical computed tomographic angiography. J Comput Assist Tomogr. 2015;39:774-80. Available from: http://www.ncbi. nIm.nih.gov/pubmed/25938211. [cited 12 Jan 2018]

24. Desai GS, Uppot RN, Yu EW, Kambadakone AR, Sahani DV. Impact of iterative reconstruction on image quality and radiation dose in multidetector CT of large body size adults. Eur Radiol. 2012;22(8):1631-40.

25. Ritter L, Mischkowski RA, Neugebauer J, Dreiseidler T, Scheer M, Keeve E, et al. The influence of body mass index, age, implants, and dental restorations on image quality of cone beam computed tomography. Oral Surg Oral Med Oral Pathol Oral Radiol Endod. 2009;108:e108-16. Available from: http:// www.ncbi.nlm.nih.gov/pubmed/19716480. [cited 12 Jan 2018]

\section{Submit your next manuscript to BioMed Central and we will help you at every step:}

- We accept pre-submission inquiries

- Our selector tool helps you to find the most relevant journal

- We provide round the clock customer support

- Convenient online submission

- Thorough peer review

- Inclusion in PubMed and all major indexing services

- Maximum visibility for your research

Submit your manuscript at www.biomedcentral.com/submit
Biomed Central 